\title{
A Mathematical Model of Heat in a Double-Skin Roof Ventilated with Natural Convection in Summer Time
}

\author{
Dragana Temeljkovski ${ }^{1}$, Goran Vučković1 ${ }^{\text {, Mladen Stojiljković }}{ }^{1}$ \\ ${ }^{1}$ Faculty of Mechanical Engineering, University in Niš, Niš (Serbia)
}

The double-skin roofs investigated in this paper are formed by adding a metallic screen on an existing sheet metal roof. The system enhances passive cooling of dwellings and can help diminish power costs for air conditioning in summer or in tropical and arid countries. This paper investigates radiation, convection and conduction heat transfers. Depending on its surface properties, the screen reflects a large amount of oncoming solar radiation. Natural convection in the channel underneath drives off the residual heat. The bi-dimensional numerical simulation of the heat transfers through the double skin reveals the most important parameters for the system's efficiency. They are, by order of importance, the sheet metal surface emissivity, the screen internal and external surface emissivity, the insulation thickness and the inclination angle for a channel width of over $6 \mathrm{~cm}$. A mathematical model of heat transfer is created for the roof with a multilayer coating which is ventilated by natural convection in the summer, that will further allow the determination of the Rayleigh and Nusselt numbers as well as air temperature and velocity profiles in several sections of channels.

Keywords: Double-skin roof; Radiation; Natural convection; Passive cooling; Solar loads

\section{INTRODUCTION}

According to the environment and energy efficiency the air conditioning of dwellings in summer increases the annual power consumption by more than 500 kWh per habitation while the invoice rises by $10 \%$. Highly reflective and ventilated double-skin roofs can be used to improve passive cooling in summer. In such a system radiation heat transfer is highly coupled with natural convection, and there is a need for a better understanding of the heat losses through double-skin roofs. Thanks to its high reflectivity, the screen must repel a large amount of solar radiation. The heat absorbed and reemitted toward the habitation is warded off by the buoyancy forces between the screen and the sheet metal: this is ventilation by natural convection. The remaining conductive heat from the sheet metal is hampered by the insulation layer underneath.

Reference [1] considers the mechanism of heat transfer in a ventilated roof, and it shows the balance of heat transfer in the ventilated roof, including conductive heat transfer from the outside to the inside of the roof due to temperature differences, radiant heat gain from the external surface, together with the convective heat transfer, when the outdoor air passes through the vent cavity. Analysed were the thermal properties of the ventilated roof, and the estimated amounts spent by installing adequate heat equation.

In this paper, heat and mass transfers in the tilted channel were numerically simulated and experimentally validated. Also investigated were the averaged Nusselt and Rayleigh numbers in the cavity, airflow rate, air temperature, air velocity in the cavity, and total heat flux through the ceiling. The aim was to determine the paramount factors for the double-skin roof efficiency, in terms of protecting the dwelling from solar loads.

\section{MATHEMATICAL MODEL DESCRIPTION}

The geometry of the model is presented in Fig. 1. The physical characteristics of the simulated materials are presented in Table 1.

\subsection{Governing equations}

\subsubsection{Within solid parts Headings}

In solid parts (metal, insulation and plaster), heat transfers are dominated by conduction. The following form of the heat diffusion equation can be considered:

$$
\rho C_{\mathrm{p}} \frac{\mathrm{D} T}{\mathrm{D}_{\mathrm{t}}}+\nabla \cdot(-\lambda \nabla T)=Q+\mu \Phi
$$

where $\mathrm{D} / \mathrm{Dt}$ is the Lagrangian derivative, $\mathrm{Q}$ is the heat source term, and $\amalg \Phi$ is the heat gained from viscous frictions. Within solids, $\mathrm{Q}=\Phi=0$ and the velocity included in the Lagrangian derivative $\mathrm{u}=0$. Then Eq. (1) gives:

$$
\rho C_{\mathrm{p}} \frac{\partial T}{\partial t}=\lambda \Delta T
$$

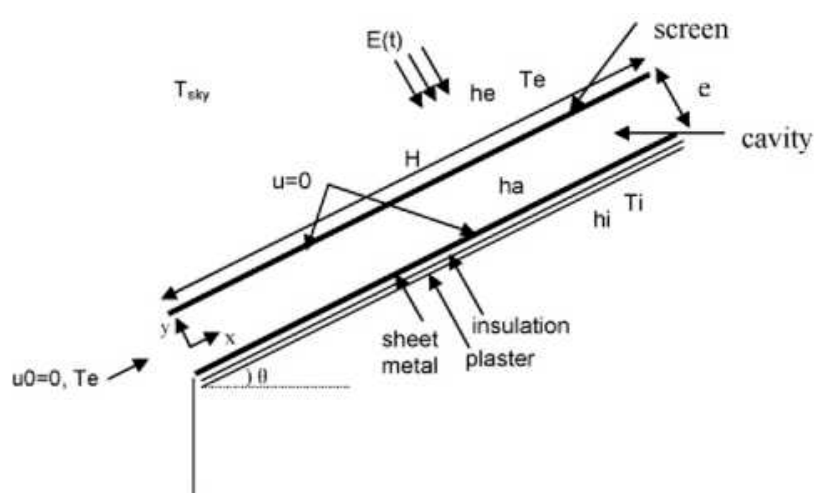

Figure 1: Main elements of the numerical model. 


\subsubsection{On surfaces}

Above the screen, we take into account solar radiation and convection terms:

$$
-\lambda_{\text {gcreen }} \frac{\partial T}{\partial y}=h_{\theta}\left(T_{\theta}-T_{g \theta}\right)+\varepsilon_{g e} \sigma\left(T_{\text {ghy }}^{4}-T_{\text {ge }}^{4}\right)+\alpha_{\text {gcreen }} E(t)
$$

where Tse is the temperature of the screen's external surface. The screen's external surface emissivity $\varepsilon s e$ is defined assuming that sky is a black body viewed under a view factor of 1 . We did not measure $\varepsilon_{\text {se }}, \lambda_{\text {screen }}$ and $\alpha_{\text {screen }}$. They were given by the manufacturer as physical properties of the sheet metal.

Beneath the screen, we take into account convection with channel's air and long wave radiation with sheet metal:

$$
-\lambda_{\text {ehrana }} \frac{\partial T}{\partial y}=h_{a}\left(T_{\text {chaneel }}-T_{g i}\right)+r\left(T_{s m}^{4}-T_{g i}^{4}\right)
$$

where Tsm is the temperature of the sheet metal cavityside surface and Tsi is the temperature of the screen's internal surface. As given by Ref. [2] and fully developed in Section 2.2, the radiation coefficient $r$ is a function of the surface emissivities of the opposing surfaces and of $\sigma$, assuming a view factor of 1 between parts of the screen and opposite parts of the sheet iron.

We have the same form above sheet metal:

$$
-\lambda_{\text {steel }} \frac{\partial T}{\partial y}=h_{a}\left(T_{\text {chaneel }}-T_{\text {sm }}\right)+r\left(T_{\text {zi }}^{4}-T_{\text {sm }}^{4}\right)
$$

Table 1: Materials physical characteristics

\begin{tabular}{|l|c|c|c|}
\hline & $\mathrm{C}_{\mathrm{p}}(\mathrm{J} / \mathrm{kgK})$ & $\lambda(\mathrm{W} / \mathrm{mK})$ & $\rho(\mathrm{kg} / \mathrm{m} 3)$ \\
\hline Sheet metal and screen & 880 & 160 & 2800 \\
\hline Air cavity & 1008 & 0,025 & 1,23 \\
\hline Insulation & 1030 & 0,004 & 15 \\
\hline Plaster & 1000 & 0,25 & 850 \\
\hline
\end{tabular}

Beneath the ceiling, we neglect long wave radiation with the room. Such an approximation is done because of the feeble impact of the long wave radiation on the air layer's temperature in the double-skin roof. Therefore, we can write:

$$
-\lambda_{\text {plaster }} \frac{\partial T}{\partial y}=h_{i}\left(T_{i}-T_{\text {ci }}\right)
$$

where $T_{c i}$ is the ceiling's indoor surface temperature.

\subsubsection{In the channel}

Temperature distribution in the channel roof is measured in order to check the temperature difference between inputs and outputs. Air flow rate is measured at the exit of the channel in order to estimate the mass flow. Through the distribution of temperature and velocity measurement of air flow is estimated by taking the heat flux channel as the thermal property of ventilation roofs [3].

Heat Eq. (1) is coupled with Navier-Stokes equations for incompressible fluids. The velocity field $\vec{u}$ in the Lagrangian derivative is given by the continuity equation and the momentum conservation equation. Density variations of the air in the channel are supposedly negligible when compared to the variation of air velocity. Therefore, the continuity equation reads:

$$
\nabla \vec{u}=0
$$

The momentum conservation equation reads, in the stationary:

$$
\begin{array}{r}
\rho \vec{u} \nabla \vec{u}=\nabla\left(\mu\left(\nabla u+(\nabla u)^{\mathrm{T}}\right)\right)-\nabla P+F \quad \text { (8) } \quad \begin{array}{l}
\text { descending and ascending radi } \\
\text { written as: }
\end{array} \\
\Phi \downarrow=R_{s m}+\rho_{s i} \rho_{s m} R_{s m}+\rho_{s i}^{2} \rho_{s m}^{2} R_{s m}+\cdots+\rho_{s m} R_{g i}+\rho_{s m}^{2} \rho_{s i} R_{g i}+\cdots \\
\Phi \uparrow=R_{s i}+\rho_{s i} \rho_{s m} R_{s i}+\rho_{s i}^{2} \rho_{s m}^{2} R_{g i}+\cdots+\rho_{s i} R_{s m}+\rho_{s m} \rho_{s i}^{2} R_{s m}+\cdots
\end{array}
$$

Given the Boussinesq approximation:

$$
\rho=-\rho_{e}\left(1-\beta\left(T-T_{\theta}\right)\right)
$$

The buoyancy force $\vec{F}$ reads:

$$
\vec{F}=-p_{e}\left(1-\beta\left(T-T_{e}\right)\right) \vec{g}
$$

\subsection{Choice of heat transfer coefficients}

Many studies have been conducted on heat transfer coefficients for heated plates and channels. But most correlations found involve plates temperature which, in our case, is not known beforehand but is an output of the computation. Consequently, upon the roof, we used the following convective heat transfer coefficient $h_{e}$ as given by McAdams [4]:

$$
h_{\mathrm{i}}\left(\mathrm{W} /\left(\mathrm{m}^{2} \mathrm{~K}\right)\right)=5,7+3,8 \mathrm{~V}
$$

In the channel, $h_{a}$ was calculated as the average value between the relations given by the French thermal regulation [5] for a vertical cavity and a horizontal cavity:

$$
h_{a}\left(\mathrm{~W} /\left(\mathrm{m}^{2} \mathrm{~K}\right)\right)=\frac{1}{2}\left[\begin{array}{c}
\max \left(0,12 d^{-0,44}, \frac{0,025}{d}\right)+ \\
+\max \left(1,25 ; \frac{0,025}{d}\right)
\end{array}\right]
$$

where, $\mathrm{d}$ is the hydraulic diameter. Here, $\mathrm{d}$ is the width of the air cavity.

$h_{i}$ in Eq. (6) is the convective heat transfer coefficient between indoor air and ceiling. As previously said, long wave radiation with the room is neglected due to its feeble impact on the roof temperature. $h_{i}$ is also calculated as the average value between the relations given by the French thermal regulation [5] for an horizontal heat flux $\left(\mathrm{h}=2.5 \mathrm{~W} /\left(\mathrm{m}^{2} \mathrm{~K}\right)\right)$ and for a downward heat flux $(\mathrm{h}=$ $\left.0.7 \mathrm{~W} /\left(\mathrm{m}^{2} \mathrm{~K}\right)\right)$ :

$$
h_{\mathrm{i}}=1,6 \mathrm{~W} /\left(\mathrm{m}^{2} \mathrm{~K}\right)
$$

Assuming a view factor of 1 between parts of the screen and opposite parts of the sheet iron, the constant $r$ for radiation heat transfers in the channel is given by Incorpera and De Witt [2] and can be demonstrated as follows:

Let be $R_{\mathrm{sm}}=\sigma \varepsilon_{\mathrm{sm}}\left(\mathrm{T}_{\mathrm{sm}}\right)^{4}$ the initial radiation flux going downward from screen to sheet iron and $\mathrm{R}_{\mathrm{si}}=\sigma \varepsilon_{\mathrm{si}}\left(\mathrm{T}_{\mathrm{si}}\right)^{4}$ the initial radiation flux going upward from sheet iron to screen.

$\mathrm{R}_{\mathrm{sm}}$ and $\mathrm{R}_{\mathrm{si}}$ are subjected to many reflexions. Let $\rho_{\mathrm{sm}}$ and $\rho_{\mathrm{si}}$ be the reflectivities of the cavity-side face of the screen and of the cavity-side face of the sheet iron, respectively. The following chain reaction occurs: the screen emits a flux $R_{s m}$ which provokes a reflective flux $\rho_{\mathrm{si}} R_{\mathrm{sm}}$ at the sheet iron surface, then another reflexion $\rho_{\mathrm{ie}} \rho_{\mathrm{t}} \mathrm{R}_{\mathrm{e}}$ on the screen and so on. All the same, the sheet iron emits $R_{s i}$, which is reflected into $\rho_{s m} R_{s i}$ and go upward again as $\rho_{\mathrm{si}} \rho_{\mathrm{sm}} \mathrm{R}_{\mathrm{si}}$...

All in all, if we assume a view factor of 1 between parts of the screen and opposite parts of the sheet iron, the descending and ascending radiation heat flux can be 
The net heat flux of a surface $\mathrm{i}$ is defined as the heat flux emitted or leaving the surface minus the heat flux absorbed or arriving by the same surface. In our case, the

$$
\Phi \downarrow \text { net }=\left(1+\rho_{s i} \rho_{s m}+\rho_{s i}^{2} \rho_{s m}^{2}+\cdots\right) \times\left(R_{s m}\left(1-\rho_{g i}+R_{g i}\left(\rho_{s m}-1\right)\right)\right.
$$

This is a geometric progression with $\rho_{\mathrm{si}} \rho_{\mathrm{sm}}$ as the common ratio number. However, the absorptivity, the reflectivity and the transmitivity of a material subjected to radiation are linked by the relation:

$$
\alpha+\tau+\rho=1
$$

All the surfaces being opaque, $\tau=0$ and Kirchoff's law for grey bodies gives $\varepsilon=\alpha$. Therefore, Eq. (16) becomes:

$$
\begin{gathered}
\varepsilon+\rho=1 \\
\text { Then: } \\
\begin{aligned}
\Phi \downarrow \text { net } & =\left[\frac{1}{\left(1-\rho_{s i} \rho_{s m}\right)}\right] \cdot \varepsilon_{g i} \varepsilon_{g m} \sigma\left(T_{g m}^{4}-T_{g i}^{4}\right) \\
& =\left[\frac{\varepsilon_{g i} \varepsilon_{s m}}{\left(\varepsilon_{s m}+\varepsilon_{s i}-\varepsilon_{s i} \varepsilon_{s m}\right)}\right]+\sigma\left(T_{s m}^{4}-T_{g i}^{4}\right)
\end{aligned} \\
\Phi \uparrow \text { net }=\mathrm{r}\left(T_{s m}^{4}-T_{g i}^{4}\right)
\end{gathered}
$$

where:

$$
r\left(\mathrm{~W} / \mathrm{m}^{2} \mathrm{~K}\right)\left[\frac{\varepsilon_{g i} \varepsilon_{s m}}{\left(\varepsilon_{s m}+\varepsilon_{s i}-\varepsilon_{s i} \varepsilon_{s m}\right)}\right]
$$

\section{BOUNDARY CONDITIONS}

Sky temperature used in Eq. (3) is defined as the temperature of a black hemisphere absorbing the same radiation flux as the sky. We kept the correlations given by Swinbank [6]:

$$
T_{\text {sky }}=0,0552\left(T_{e}\right)^{1,5}(K) \quad \text { for a clear sky }
$$

The thermal boundary conditions in the channel are as follows: external temperature $T_{e}$ imposed at the entry of the channel. To achieve numerical convergence with an unknown exit temperature, a condition on the convective flux was specified at the channel exit, meaning that in (1),

$$
-\lambda \nabla T \cdot n=0
$$

The total heat flux is then limited to its convective part:

$$
q \cdot n=\rho C_{\mathrm{p}} T_{\mathrm{u}} \times n
$$

A no-slip condition of the fluid on the side plates of the channel was imposed as the dynamic boundary condition. Therefore, the air velocity equals zero on the plates. In order to numerically simulate the exit gap, the total force on the exit boundary was set to zero. Therefore, in Eq. (5),

$$
T=\left[-p l+\eta\left(\nabla u+(\nabla u)^{T}\right)\right]=0
$$

In order to help numerical convergence and simulate efficiently adverse summer condition with no wind, the air velocity at the cavity entry was initialized as nil. The screen, cavity and sheet iron initial temperature is $\mathrm{T}_{\mathrm{e}}$. The insulation and plaster initial temperature is $\mathrm{T}_{\mathrm{i}}[6]$.

\subsection{Grid and computation}

The computation was done with a finite elements method [7]. For a better computation of near-the-wall heat and mass transfers, the grid was quadrilateral and refined near the borders of the channel. The analysis was stationary. In order to respect the full coupling between net descending flux is obtained by doing (13) and (14). One obtains:

heat and mass transfers' non linear equations, the equations presented above (in channel and solids) were solved simultaneously to produce temperature and velocity fields.

\section{CONCLUSION}

This paper describes a model of a double-skin roof with natural convection. This is a mathematical model of heat transfer. The model was first set for solid parts of the system, as follows: metal, insulation and plaster. The next stage wasdefined by the equation of heat transfer surfaces above the screen taking into account solar radiation and convection expressions. At the end of the channel, an incompressible fluid was examined with the aim of determining the downforce. The selection of heat transfer coefficient for applied materials and set conditions was made from the available literature where many studies have thermal coefficients of determination when crossing the heated plates and channels. Then, the equations governing heat and mass transfer through the roof were presented and boundary conditions were simulated. For the validation of the assumptions, the results from the numerical model will be compared with experimental measurements which are planned for further research. After experimental validation, necessary corrections will be made to the mathematical model and the corrected numerical model results will be used to perform parametric studies with the real dimensions of the double roof structure.

\section{REFERENCES}

[1] D.D. Temeljkovski, G. Vučković, '’Mechanism of Heat Transfer in Ventilated Roof'’, pp 183-188, $2^{\text {nd }}$ International Scientific Conference COMETa 2014, Jahorina, B\&H, Republic of Srbska. (2014)

[2] F.P. Incorpera, D. De Witt, Fundamentals of Heat and Mass Transfers, fourth ed., Wiley \& Sons, New York, p.738, (1996)

[3] Sunwoo Lee, Sang Hoon Park, Myong Souk Yeo*, Kwang Woo Kim. An experimental study on airflow in the cavity of a ventilated roof, Building and Environment 44, p. 1431-1439. (2009)

[4] W.H. McAdams, Heat Transmission, McGraw-Hill, New York, (1954)

[5] Thermal Regulation 2000 (RT 2000), rules Th-U, leaflet 4/5 (In French), pp. 4-6 (Chapter II), (2000)

[6] P.H. Biwole, M. Woloszyn, C. Pompeo, ''Heat Transfers in a double-skin roof ventilated by natural convection in summer time', Energy and Building, Elsevier, Vol. 40, p.p. 1487-1497, (2008)

[7] Javier Muñoz , José M. Martínez-Val, Rubén Abbas Thermal regimes in solar-thermal linear collectors, World Renewable Energy Congress 2011 - Sweden, Solar Thermal Application (STH), Linkoping, Sweden, pp 3905-3912, (2011) 


\begin{tabular}{|c|c|}
\hline \multicolumn{2}{|c|}{ Nomenclature } \\
\hline$a$ & thermal diffusivity $\left(\mathrm{m}^{2} / \mathrm{s}\right)$ \\
\hline $\mathrm{C}_{\mathrm{P}}$ & specific heat capacity (J/kg K) \\
\hline$e$ & roof width $(\mathrm{m})$ \\
\hline$E$ & solar radiation $\left(\mathrm{W} / \mathrm{m}^{2}\right)$ \\
\hline$F$ & Buoyancy force $(\mathrm{N})$ \\
\hline$g$ & gravitational acceleration $\left(\mathrm{m} / \mathrm{s}^{2}\right)$ \\
\hline$h_{a}$ & $\begin{array}{l}\text { convective heat transfer coefficient in the } \\
\text { channel }\left(\mathrm{W} / \mathrm{m}^{2} \mathrm{~K}\right)\end{array}$ \\
\hline$h_{e}$ & $\begin{array}{l}\text { convective heat transfer coefficient between } \\
\text { outdoor air and screen }\left(\mathrm{W} / \mathrm{m}^{2} \mathrm{~K}\right)\end{array}$ \\
\hline$h_{i}$ & $\begin{array}{l}\text { convective heat transfer coefficient between } \\
\text { indoor air and ceiling }\left(\mathrm{W} / \mathrm{m}^{2} \mathrm{~K}\right)\end{array}$ \\
\hline$H$ & roof length (m) \\
\hline$n$ & vector normal to a surface oriented outwardly \\
\hline$N_{u}$ & Nusselt number \\
\hline$P$ & pressure $(\mathrm{Pa})$ \\
\hline$R_{a}$ & Rayleigh number \\
\hline$R_{e}$ & Reynolds number \\
\hline$T$ & temperature (K) \\
\hline$T$ & outdoor air temperature (K) \\
\hline$T_{i}$ & indoor air temperature (K) \\
\hline $\mathrm{T}_{\text {sky }}$ & sky temperature (K) \\
\hline$u$ & air velocity field $(\mathrm{m} / \mathrm{s})$ \\
\hline Greek & letters \\
\hline$\alpha$ & absorption coefficient for solar radiation \\
\hline$\beta$ & coefficient of thermal expansion $\left(\mathrm{K}^{-1}\right)$ \\
\hline$\varepsilon$ & surface emissivity \\
\hline$\lambda$ & thermal conductivity (W/m K) \\
\hline$\mu$ & dynamic viscosity (Pa s) \\
\hline $\mathrm{V}$ & cinematic viscosity $\left(\mathrm{m}^{2} / \mathrm{s}\right)$ \\
\hline$\Phi$ & heat flux density $\left(\mathrm{W} / \mathrm{m}^{2}\right)$ \\
\hline$\rho$ & density $\left(\mathrm{kg} / \mathrm{m}^{3}\right)$ \\
\hline$a$ & $\begin{array}{l}\text { Stefan-Boltzmann constant: } a=5.67 \mathrm{E}-8 \\
\mathrm{~W} /\left(\mathrm{m}^{2} \mathrm{~K}^{4}\right)\end{array}$ \\
\hline$\theta$ & roof slope $\left(^{\circ}\right)$ \\
\hline \multicolumn{2}{|c|}{ Subscripts } \\
\hline $\begin{array}{l}S_{e} \\
S_{i}\end{array}$ & $\begin{array}{l}\text { characteristic at the screen external surface } \\
\text { characteristic at the screen internal surface }\end{array}$ \\
\hline $\mathrm{S}_{\mathrm{m}}$ & characteristic at the sheet metal surface \\
\hline
\end{tabular}

